\title{
Improving Teaching by Reflecting on Practice ${ }^{1}$
}

\section{Ronald Smith}

Concordia University, Montreal, Quebec

\section{Fred Schwartz ${ }^{2}$}

Vanier College, Montreal, Quebec

Improving teaching requires that both faculty members and faculty developers reflect on their practice (Smith, 1983; Smith and Schwartz, 1986). In this paper we want to report on our efforts as faculty developers to help faculty members reflect on difficult situations in their practice. This reflection on practice involves discovering problems, inventing and implementing solutions, and evaluating their effectiveness. Our approach connects reflection and action and is derived from the theory-of-action approach of Argyris and Schon (1974) and the work on reflective practice by Schon $(1983,1987)$.

Schon (1983) proposes "reflection-in-action" as a way of describing how professionals think and act in the complex and ambiguous situations in their practice. When their usual skilled responses don't work, they impose new meanings on the situation in order to make sense of their difficulties. The meanings they impose become the frameworks or "frames" within which they act. These frames determine what they attend to and what they ignore; where they focus their attention and what they accept as movement towards a more satisfactory situation. Professionals take action and they evaluate the success of their actions in terms of how they have framed the problem or puzzle. Schon calls these actions "experiments." Each experiment is assessed in terms of the degree to which it has

From To Improve the Academy: Resources for Student, Faculty, and Institutional Development, Vol. 7. Edited by J. Kurfiss, L. Hilsen, S. Kahn, M.D. Sorcinelli, and R. Tiberius. POD/New Forums Press, 1988. 
improved the situation, led to the discovery of new meanings, or changed the nature of the questions to be explored. Experimenting in the world of practice continues until the problematic issue which initiated the experiment is resolved.

In our work with faculty we asked them to reflect on the difficult situations in their practice in order to identify how they had been reflectingin-action. Effective reflection in and on action is rigorous; it both generates knowledge which is useful to practice and resolves the difficult situation. "Rigor" refers to the extent to which the process generates valid information. In reflection, as in all good research, conclusions must be connected to data; they must also be subjected to tests of disconfirmation. If reflection is based on information which is not valid, then it will lead to errors. For example, consider a teacher who interprets a student's poor performance as evidence of a lack of motivation. If the attribution is false and the teacher assumes and acts as if it were true, the teacher's way of reasoning and acting is likely to lead to misunderstanding and ineffective communication and problem solving.

Reflection on practice must also generate knowledge that will lead to more effective action. The success of our reflection both on and in problematic situations can be measured by the extent to which we will be able to generate new actions which resolve the difficulties and improve practice. Our reflections will be inadequate to the extent that they produce insight, theory, or knowledge which does not or cannot lead to new actions.

The way professionals think and act in difficult situations in their practice and the way they reflect on those actions is determined by their "theories of action." The "theory-of-action" concept was developed by Argyris and Schon(1974) and proposes that individuals:

...design actions to achieve intended consequences, and monitor themselves to learn if their actions are effective. They make sense of their environment by constructing meanings to which they attend, and these constructions in turn guide action. In monitoring the effectiveness of action, they also monitor the suitability of their construction of the environment (Argyris, Putnam, and Smith,1985, p.81).

When people fail to achieve their intentions they need to reflect on their theories of action; that is, how they have constructed their meanings and how they have designed their actions.

The data for this article are drawn from a 3-day workshop we conducted to help faculty become more effective in dealing with difficult issues in their teaching practice. We asked faculty to reflect on their practice in order to identify the theories of action that had been informing their 
practice. We have organized our interventions in the workshop under seven broad headings: Identify a difficult situation, Generate data, Build a diagnosis, Develop and expand it, Move from diagnosis to action, Surface basic values, and Reframe the situation. We conclude the paper with an examination of the effectiveness of a theory-of-action approach to reflecting on difficult issues in teaching in order to improve practice.

\section{Step 1. Identifying a Difficult Situation.}

Effectiveness can be defined as the extent to which the consequences of our actions match our intentions. Participants were asked to pick a problematic situation, one where they felt they had not been as effective as they wanted to be, one where they felt disappointed in the outcome or felt stuck with respect to what they might have done differently to improve the situation. What is important here is that each of the participants be personally involved so that they are more likely to be committed to learning and to the outcome of the problem solving.

\section{Step 2. Generating Data.}

Information about what individuals were saying, thinking and feeling in the difficult situations in their practice provides the data which are required to identify the participants' theory of action, that is, how they were reasoning in order to act the way they did (Argyris and Schon, 1974). The participants were asked to write up a case study from their teaching practice which described:

a) a difficult and important problem in their teaching,

b) the strategies they used to try to solve it,

c) the barriers they encountered, and

d) a sample of actual conversation that illustrates the problem in a two-column format. On one side of the page they were to write what was said, on the other side any thoughts or feelings that were withheld.

All our illustrations in this article are based on a case which was written by $\mathrm{K}$, one of the participants in the workshop. The case she wrote is reproduced below:

\section{The Case of the Scowling Student}

a) Problem: Student who did good work in my class but frequently attempted to show off in class by coming forth with ir- 
relevant information. Student seemed to scowl at me continuously. Made me feel very uncomfortable. I didn't scan his area of the classroom. I experienced that class as less pleasant to a certain extent because of him. Every interchange we had in class was experienced by me as a test of my authority, as radiating hostility from the student.

b) Strategies: I tried to ignore the situation. Said nothing to the student.

c) Barriers: Are students "responsible" for their facial expressions? Was my "interpretation" - this is a scowl - valid? (You're too sensitive.)

d) Conversation: Eventually, on the last day of classes, when I returned graded essays, this student "complained" (then denied he was "complaining") that I gave his paper an A-. This situation occured while two or three other students were trying to speak with me - they were expressing how much they enjoyed the class.

I lost some control and finally said something about what had been disturbing me all semester long: a) the tense interchanges and b) the scowl.

What I Thought or Felt But Did What I and Other Actually Said Not Say

1. I felt hostility coming from the student. I wasn't sure what it was about.

2. His facial expression and comments made me uncomfortable and irritated.

3. Decreased my usual pleasure in teaching that class.

Me: If you want to contest the grade, there's an appeals procedure.

Other: I'm not complaining about the grade. I just want to know why you gave me an $\mathrm{A}$-.

Me: As you can see, if you read the essay and my comments in the body of the text and at the end, you'll find out what I think are the paper's strengths and weaknesses.

4. Wanted to discuss it but felt too uncomfortable.

Other: Yes, but I want to know why you gave me an $\mathrm{A}-$. It doesn't seem fair. I don't think you like me. 
Me: I think you should re-read the essay and read my comments and think about them and then come and discuss it with me in my office, in private.

Other: Can I see you now?

Me: I don't have office hours today-I'm in class till 10:00 tonight.

Other: Well, when can I see you?

Me: My office hours are on Mondays.

Other: That's too long to wait. I think you just don't want to see me.

Me: This is not the time or place to discuss this.

Other: But when can I see you? You're making it very difficult.

Me: (Very angry.) You're being impossible. You can't always get your needs met instantly. You should learn to think about your behavior and its consequences. You've been scowling at me all semester.

Other: Me? Scowling? I was just concentrating. I really enjoyed this class.

Me: If you want to discuss this further, come to my office during my office hours.

\section{K's Analysis of Her Behavior}

I really feel I mishandled this situation. I should have asked to see the student early in the semester and asked him how he felt about me and about the class. I then should have raised the question of his "scowling". He might have denied it, questioned my interpretation, but I would have had some satisfaction in express- 
ing my discomfort and raising the issue as a case of classroom etiquette.

This description of K's problem situation provided the data required to begin to identify K's theory of action. The way we worked with $\mathrm{K}$ and the other participants is reported in the sections that follow.

\section{Step 3. Building the Diagnosis.}

Our approach to identifying K's theory of action requires that we develop a diagnosis of how $\mathrm{K}$ was reasoning in her case in order to have acted as she did. In K's case we have her diagnosis: she mishandled the situation by not calling the student in earlier and raising the question of his scowling. We and all the other participants agreed with $\mathrm{K}$ in this regard. However, from the theory-of-action perspective this diagnosis is incomplete. The challenge in building a theory-of-action diagnosis is to identify how $\mathrm{K}$ was reasoning at that time in order not to do what she now sees so clearly as more effective action.

This diagnosis must be built in ways which are consistent with the generation of valid information; that is, it must be connected to the data in the case and tested for disconfirmation. In step 3a we illustrate some of the interventions we made in the workshop in order to make K's reasoning explicit and in step $3 \mathrm{~b}$ we try to organize K's reasoning.

\section{Step 3a. Making Reasoning Explicit.}

Building the diagnosis required that we make sense out of how $\mathrm{K}$ constructed her difficulty in the case. We did this by asking questions designed to get the participants to make their reasoning explicit and by illustrating our own reasoning. More specifically, this meant stating the premises and inferences upon which conclusions were based. Our questions were designed to get participants to illustrate any attributions, evaluations or judgments with data from the case. We continued to ask questions until we were satisfied that the reasoning (premises, inferences, and conclusions) was explicit enough that it could be disconfirmed by other participants, by us, or by $\mathrm{K}$.

The following two excerpts were selected from the transcript of the workshop as illustrations of how we intervened to get the participants to make their reasoning explicit or to make our reasoning explicit. The column on the right provides our interpretations of the workshop dialogue on the left. In the dialogue "I" refers to either of the workshop leaders, 
$\mathrm{K}$ refers to the author of the case, and the other letters refer to other participants in the workshop.

\section{Excerpt A}

\section{Workshop Dialogue}

I. You were saying earlier she feels her authority is threatened, she feels uncomfortable. What does she do?

M. During the semester she is immobilized, backed into a corner.

I. What does she in fact do?

M. Nothing. She doesn't do anything. She avoids his gaze in class.

I. Okay. She avoids his section in the class and therefore looking at him. What else does she do?

M. She tries to ignore the situation.

I. The situation being the scowling?

M. And the testing of her authority.

I. Avoids confronting the testing of her authority and withholds she is doing this. She does it and she doesn't say she is doing it... These are strategics for dealing with her uncomfortableness. So she withholds that this is what she is doing.

\section{Our Interpretations}

I repeats participant's comments and asks for specific behaviors.

M provides an unillustrated evaluation/judgment.

I requests illustrations from case data.

M illustrates the "nothing" with case data.

I acknowledges the illustration and asks for any others.

$\mathbf{M}$ gives another illustration.

I checks the meaning of "situation."

$M$ extends her meaning with more data from case.

I attributes intention to $\mathrm{K}$ and identifies an action strategy (that $\mathrm{K}$ and others may be unaware of and which will need to be checked.) 


\section{Excerpt B}

\section{Workshop Dialogue}

I. She says "I feel my authority is threatened." Is that the language she uses?

$P$. "Every exchange in the class is experienced by me as a test of my authority."

I. It would be more accurate to say that she experiences her authority as being threatened. Would you accept that she doesn't test that the authority is being threatened?

P. Yes.

I. She assumes this is true and doesn't test it. She assumes and acts as if it were true. Would you accept that?

P. I think she acts as if it were true. I have a problem with how would she test it?

Explicit reasoning requires that all attributions, evaluations, and judgments be illustrated with data from the case. Our interventions were designed to get the participants to make their premises and inferences explicit and to illustrate and test our inferences and conclusions.

\section{Step 3b. Organizing the Reasoning.}

One way to represent the reasoning that informs action is to develop maps which indicate the consequences that flow from the strategies chosen to deal with specific situations. The maps below are based on the previous excerpts. 
Excerpt A Map

student scowling

feels authority

is threatened

feels unconfortable

$>$ ignore scowling

$>$ avoid his section

of class

$>$ doesn't confront
Situation $-\rightarrow$

Action Strategies - $\rightarrow$

$>$ and witholds she

is doing all of this

\section{Excerpt B Map}

\section{Situation $-\rightarrow$}

\section{Action Stages - $\rightarrow$}

when $\mathrm{K}$ experiences

student as attempting

to test her authority

$$
>\text { doesn't test }
$$

$>$ act as if she is correct

\section{Consequences}

$>$ feels immobilized and frustrated

$>$ no change in

situation

\section{Consequences}

$>$ misunderstanding

$>$ misunderstanding

$>$ little learning or change

\section{Step 4. Developing and Expanding the Diagnosis with $\mathrm{K}$.}

So far in the workshop $\mathrm{K}$ had written up a case of a difficult teaching issue and we had worked with the other participants to build a diagnosis of K's problem, while $\mathrm{K}$ listened. We then invited $\mathrm{K}$ to react to our diagnosis. Essentially K's reactions could be characterized as 1) confirming parts of the diagnosis, 2) adding information or correcting misunderstandings, 3) identifying important learnings and 4) acknowledging the consequences of her actions. We want to illustrate these reactions with excerpts from the transcript.

\section{Workshop Dialogue}

I. My advice to you would be for you to be hard on us. By hard I mean make us illustrate our judgments. The other thing is make us produce our advice. ... don't let us get away easily by just giving you abstract advice.

\section{Our Interpretations}

I invites $\mathrm{K}$ to confront our disgnosis and to go beyond it to action. 
K. O.K. I mean this is hard but I don't think I feel too defensive about it. That stuff about "avoids his section of the class," "ignores the situation," seems totally correct...makes a lot of sense to me.

(later on)

$K$. And by adding the part that this is withholding, that adds new information. I knew already about avoiding more confrontations. I didn't realize until you said it that this is a form of withholding. I think that is a serious addition to what was going on there.

(later on)

K. My position was immobilized in that it left all of those things (unsaid). I feel quite comfortable with that.

\section{(later on)}

K. I did not experience my authority as being threatened. I experienced the student as attempting to threaten my authority with his questions and statements.

\section{(later on)}

$\mathrm{K}$. What was going on there, what I believe is true as you have stated it, is that I assumed stuff about what that meant for the student, I didn't inquire, I didn't test it. I acted as if it was true. All that is quite true.
$\mathrm{K}$ acknowledges her difficulty in staying open to learning and confirms her strategy.

$\mathrm{K}$ identifies becoming aware of her withholding as an important learning.

$\mathrm{K}$ acknowledges consequences in diagnosis.

$\mathrm{K}$ modified the diagnosis.

$\mathrm{K}$ acknowledges the meanings that we imposed on her reasoning and behavior. 
1. What we're trying to do here is understand your reasoning about what the student did and to trace it through to your getting angry, and feeling immobilized. It probably happens quickly. There is a sequence there in how you make meaning of this student's shrugs.

K. I see that. I made assumptions about what his verbal and non- verbal behavior meant which I did not test. I simply assumed that this is a scowl. The asking of questions, the showing off. I was really certain that the remarks he made to the class were intended to be irrelevant.

I. You're doing more than that. If we pick up the anger, and you experienced the class as less pleasant and blamed the student for that, you're holding your student responsible. You close that off as the case was written.

K. There were times when he wasn't there when I felt the class was much more pleasant. But that doesn't prove that his presence is responsible for my feeling. And with all this additional information, then I can own my responsibility for not making that class less problematic.

I. I think this diagnosis is also saying how you disempowered yourself.
I restates our strategies for building a diagnosis.

$\mathrm{K}$ acknowledges her untested attributions and evaluations.

I extends the diagnosis by identifying K's responsibilities for the outcome.

$\mathrm{K}$ acknowledges her reponsibility.

I identifies K's feelings of helplessness and lack of responsibility as the consequences of her way of reasoning in the situation. 
K. Yes.

\section{(later on)}

$\mathrm{K}$. What I'm trying to get at is something that was uncertain to me before we started all this and still is a little uncertain. I know that different people respond in different ways, people are more aggressive, question more, and so on. It's within the realm of possibility that his behavior, his way of asking questions and so on was not intended by him as a test of my authority or anything like that. I accept that these are attributions about hostility.

By illustrating our diagnosis of K's reasoning and action and then checking with $\mathrm{K}$ for disconfirmation, we were able to generate with $\mathrm{K}$ a diagnosis which she accepted as valid. She acknowledged that it gave her new insights into the counterproductive ways she had been reasoning and acting. If we are to be helpful to $\mathrm{K}$ we must work collaboratively with her to generate information about her actions which she accepts as valid, since $\mathrm{K}$ will be the one who ultimately takes the actions to improve her practice.

\section{Step 5. Moving from Diagnosis to Action.}

Problem solving in action science involves not only diagnosing the problem but also inventing and producing actions to solve the problem. A considerable amount of time was spent on generating diagnoses for K's case. The diagnoses suggested that $\mathrm{K}$ made attributions and evaluations that she didn't test, she withheld these attributions and evaluations and withheld that she was withholding them; yet she behaved as if they were true. This strategy was self-sealing. It led to immobilization and feelings of frustration, uncomfortableness, and helplessness; yet none of this was discussed. K's efforts to control this situation, both her behavior in the 
class and her emotional reactions, eventually caused her to do just those things she was trying to avoid ("I lost some control and finallly said something about what had been disturbing me all semester") and to hold the student responsible. K acknowledged this diagnosis and following the advice we had given her, eventually said to the group.

Well from the beginning, the first or second time there would be an interchange between the student and me that made me feel uncomfortable, where something he says or his non-verbal behavior is triggering some negative feelings in me, I want to ask my consultants what they think I should have done at that point.

The excerpts which follow illustrate the suggestions offered by several of the participants for what $\mathrm{K}$ might say to the student. We wanted to ensure that these suggestions were at the level of productions (the words $\mathrm{K}$ could say to the student) and not at the level of inventions (abstract recommendations such as "be direct" or "confront"). We assessed these productions by the same criteria we had used on K's case; that is, were the attribu tions, evaluations, and judgments illustrated and publicly tested.

\section{Workshop Dialogue}

B. I think you answered some of it yourself at the end of the case. You did some testing by actually confronting him and saying "you've been scowling at me all semester."

\section{Is that what you are advising her} to say?

B. Well at the very end, after she had gone through all of this emotion with anger she asked that. But if she had asked him before (she experienced the anger)....

K. I wouldn't say that at this point (in the semester) because we're still having questions about my interpretations of his actions. He may respond with this look when he is concentrating.

\section{Our Interpretations}

$B$ recommends $\mathrm{K}$ state her evaluation (without illustration or inquiry.)

I conforms that B is recommending this as a production.

B recommends doing it earlier, before the anger builds up. B doesn't say how to "ask."

$\mathrm{K}$ rejects this now because she is not confident that his look is, in fact, a scowl.

(later on, in response to B's suggestion) 
K. I wouldn't put it like that now. I would have been much more active. I would have asked to see him privately because I feel uncomfortable doing that kind of thing (in class). But I'm not sure how I would have put it.

I. Let's give this person a name. "Harry, you just asked me a question, I thought I gave you an answer and now I see you reacting in a way that I don't understand. Can you help me understand what it is about my answer that leads you to whatever, slump or scowl, or frown?"Would you say that to him?

K. Yeah that's better. "I wasn't slumping, scowling, or frowning. I just dropped my pencil."

M. You think he would deny it. You don't believe his answer.

K. I don't believe it was a look of concentration.

M. How about if we focus on basically how his behaviors affect you.

\section{Produce it, $M$.}

M. "Harry, yesterday in class when you asked this and I told you about the various citations, you went like (non verbal). That really jolted me. I didn't understand whether that was a signal of defiance, whether you were angry with me and it really put me off. Did you mean to do that?

Our interventions at this stage were designed to get the participants to try to produce their solutions, to generate the words they would say to
$\mathrm{K}$ is uncomfortable with confrontations in class, and doesn't know what to say in private.

I offers a production which invites the student to help clarify gaps in I's understanding of the situation. I illustrates the gap with data.

K believes the student will disagree with her interpretation by offering an "acceptable" explanation.

B. Two participants, $M$ and $B$, infer that $\mathrm{K}$ will hold her interpretation as the true one and will discount or not believe the student.

M suggests a strategy.

I asks what $M$ would say.

M's production starts by accepting as true at least one of her interpretations of the student's behavior (defiance, anger). $M$ identifies the consequences (jolted, put off) that follow. $M$ inquires about the student's intentions (but not about the accuracy of her interpretations). 
the student, and we offered our own suggestions. One criterion for a good diagnosis is that it leads to more effective action. If the diagnosis of K's problem is that she did not illustrate or test her attributions or evaluations (and $\mathrm{K}$ agrees) then the actions to solve K's problem would involve illustrating and testing.

However, the situation is complicated. It is not enough to "learn" new strategies (illustrate and test) without changing the underlying governing values. Illustrating and testing can be used to try to control the student rather than to generate valid information. A statement like "the student will deny it" indicates to us that $\mathrm{K}$ and the other participants still hold their interpretations as the truth and will only accept the student's acknowledgement of their truth as a satisfact ory solution. To say this another way, their goal was to control the situation and the student, to get him to agree with their interpretation, rather than to subject their interpretation to a real test. This point is illustrated in the following excerpt:

\section{Workshop Dialogue}

I. The piece I'd like to pick up on is that (you) assume it's true and that he'll agree when you say "When you went like that (non verbal)." I would check that first.

K. In what way?

I. By check I mean "I saw you go like (non verbal). Do you agree you did that?" Was he even aware he did that?

M. Okay, your intention is a bit different from mine. I have a devious intention, that is, even if he denies it, damn right he's not going to do it again in the next class... You have a much more constructive intention. Your intention is to really verify information. My intention is just to let him know that I'm really watching him. He's going to be called for it.

\section{Our Interpretations}

I points out another level of assumptions that needs to be tested.

K asks how to "check".

I illustrates one way to check the assumption.

$M$ reveals that her goal (or governing variable) is to control the student's behavior in class.

This is not to suggest that K's original interpretation may not have been accurate nor that the student would not deny it. Rather it is to say that action in the service of valid information and informed choices (by 
both $\mathrm{K}$ and the student) would look for ways to disconfirm one's conclusions rather than label the other's answers as denials.

If the teacher tries to control the student by making evaluations and attributions which she is unwilling to test, yet behaves as if they are true, then we would say that the teacher is behaving defensively and is not open to learning. She is protecting her interpretations and is not willing to listen to other points of view or to examine what it is in her behavior that might be producing the student's reactions. The teacher's controlling behavior may very well lead the student to get angry or defensive, or withdraw from learning, but we would argue that the teacher's reasoning and behavior are partly responsible for producing these consequences.

\section{Step 6. Surfacing Underlying Values.}

The participants acknowledged that their strategies (such as not illustrating or testing their attributions) were likely to lead to counterproductive consequences (miscommunication and misunderstandings) for effective problem solving. However, they were unable to create, during the brief period of the workshop, any sentences for $\mathrm{K}$ to say to the student which either we or they considered satisfactory. They agreed that valid information was a necessary criterion for effective problem solving. Yet they continued to produce sentences which, when challenged, even they would agree were inconsistent with the goal of generating valid information.

We believe that the participants were unable to produce "effective solutions" because of the basic values which governed their actions. Through discussions in the workshop and readings, we advocated that behavior such as not illustrating or testing your evaluations and attributions is consistent with trying to win unilateral control of the situation and the student. Behavior such as withholding your discomfort or anger and withholding that you are withholding it are strategies consistent with trying to protect yourself and the other person and to avoid dealing with negative emotions.

Acknowledging that one is ineffective is difficult, but it is even more difficult to accept that the reasons for your ineffectiveness are underlying values which are inconsistent with what you espouse. This is reflected in some of the comments made by the participants during the workshop:

$K$. The more I think about it the more I'm skeptical that I failed to act in so many ways....the psychologizing of it really bothers me a bit....some very nasty assumptions underlying my thinking....loss of control was loss of my self control, not I think 
loss of control the way Argyris (1982) means it....I'm uncomfortable with the psychologizing about everything that was going on in my head and what it means.

(later on)

K. I came away from yesterday feeling that I had really laid myself on the line in that particular case with these people that I don't know and wow! That really felt hard....reading that paper (Argyris) and not knowing any of that stuff made me feel even worse about my failure....I really failed....

I. And felt ashamed.

K. Yes.

(later on)

B. How do you deal with your sense of shame? Not just ashamed of having blown it, but to be ashamed of the reason. $\mathrm{K}$ shared it with us. She feels even worse because it's not just her, it's in this room (public). I'd feel very bad about things like that.

Discovering that your behavior is inconsistent with the values you espouse can be surprising and upsetting. If your governing values are to be in control, to protect yourself, to win, then discovering these inconsistencies in public can be painful. You cannot avoid the pain by denying the inconsistencies if you have collaborated in the diagnosis and believe it to be fair and accurate.

\section{Step 7. Reframing the Situation.}

If either we or $\mathrm{K}$ try to avoid the pain or embarrassment, then we are likely to shut down inquiry and learning. Our strategy was to acknowledge $\mathrm{K}$ 's feelings and to connect these feelings to the way she was thinking about her "failure." We tried to offer her new ways to think about her situation, to "reframe" it in ways which would lead her to more learning and to less pain. We reframed the concepts of competence and error in ways that were consistent with generating valid information and effective problem solving.

I: Yes, I think you will feel that way. I think part of it has to do with your conception of what it means to be competent. Most of the time, I am very successful in doing what I try to do. Once in a while, I blow it. Those are the things that I pay all my attention to now. And, for me, how I deal with those issues becomes the measure of my competence. It's not that I blew it, because we'll all blow it sometime, nobody has that level of perfection. It's what we do when we blow it. The tendency is to hide it (your 
incompetence and failure) and cover it up and that just makes it worse because you don't learn from those situations. What you do is you go inside and you say "Oh no, I blew it," without getting any data from other people who might have the information. So that if you can, and I don't think that this is easy, change your behavior to think about competence as what do I do when I make a mistake? Mistakes are opportunities to learn. We keep telling our students that. Don't be afraid to make a mistake - it's just an opportunity to learn. Argyris and his colleagues have developed an elaborate map for looking at errors called "Dilemmas of Learning" (Argyris, Putnam, and Smith, 1985, p. 276)...One way is to view errors as puzzles. I'm upset that I blew it here but it's a puzzle and it's an opportunity to learn so I'm going to dig in. Another way is to view errors as crimes to be covered up, so you should hide when you're wrong. The latter frame around error will get you into trouble in terms of learning and problem solving. It's our intention to help you learn by examining how you are reasoning. That may make you uncomfortable at times. But it is not our intention to make you uncomfortable; it is to help you learn.

K: I know that and I didn't feel I was being attacked. I certainly offered myself.

The excerpt above advocates a different way of thinking about competence and error. The next excerpt illustrates how a commitment to generating valid information can be the criterion by which disagreements and denials are resolved. It reframes "confronting the student" as inquiry in the scrvice of learning and problem solving.

M: The part I don't understand is: "Is it (your conclusion) only valid when the other person agrees that you and he have the same interpretation?"

I: No, absolutely, not.

M: What are the other ways that you can say that I have valid information even though they are denying it?

I: You present the data and your interpretation and you ask them to disconfirm it. You don't want to make the standard just that the other person agrees with you. Because that allows the other person to control you. All they need to do is say, "No, you're wrong." What you want to do is check the data, and your interpretations. So the person says, "I don't agree." So you answer, "What explanation do you have to account for this behavior? Give me another explanation. I'm willing to accept that mine might be wrong, but I want to know what explanation might 
be right." The person says, "I don't have any idea," or "You're just wrong." Then I would say, "I don't see how I can help you learn if you continue to behave in this way and don't offer any explanation." You don't give the person the power to control you by simply disagreeing with you. You say, "What information do you have that would contradict my reasoning?" I've data, logic, and conclusions. You have said "I don't agree. I understand that you don't agree. What is it that you don't agree with? You don't agree with the data?" He says, "Oh no, I did that." "You don't agree with the reason?" He says, "Oh yeah, I agree with that." "You don't agree with the conclusion?" Then, "Tell me how you get from here to someplace else." And I think then you're tough, and if the person is unwilling to present other data, reasoning, or conclusions, and continues to disagree, then I would say, "I don't know any way to work with you to resolve our differences."

So far in this paper we have demonstrated how our frames about increasing professional effectiveness and problem solving informed our strategies in one segment of a faculty development workshop. We illustrated how we were reflecting in the action of the workshop. In summary, our interventions were designed to have participants

1) identify a problematic situation of some importance,

2) generate data about their actions in the situation and their interpretations of those actions,

3) build a diagnosis of the problem which makes the underlying reasoning explicit and organize it into an action map,

4) develop, refine, and expand the initial diagnosis,

5) move from the diagnosis to the invention and production of new actions to solve the problem,

6) examine these new actions and surface any inconsistencies with espoused values and beliefs, and

7) consider alternative ways of thinking about and acting in problematic situations in such a way as to promote more effective problem solving and learning.

\section{Our Reflections on Our Actions}

All our actions in the workshop can be interpreted as experiments initiated in view of how we had framed the problem of helping professors to improve their teaching. We now want to reflect on our actions in the workshop by presenting our inter pretations and assessments of the participants' reactions. 
We framed the solution to the problem of increasing teaching effectiveness as being: reflect on your practice in difficult situations. Since how professionals reflect on their practice is determined by their theories of action, our actions were designed to identify the counterproductive features in the teacher's behavior and in the underlying reasoning that informed that be havior.

All our actions in the workshop could be seen as action experiments designed to test the adequacy of our way of framing the solution to the problem of improving teaching. These tests were carried out in ways to ensure that both we and the participants agreed we had generated valid information. This is essential to ensure rigor in action experiments.

As we interpret the results of our experiments, we believe we were successful in getting the participants to recognize and accept their action strategies of making attributions and evaluations without illustrating or testing them, and of behaving as if these were true. They acknowledged the counterproductive consequences of these strategies for learning and problem solving. However, the participants were unable to produce more effective actions even after they were aware of alternative strategies such as illustrating and testing attributions and evaluations.

This outcome leads us to the conclusion that our original frame was incomplete. The identification of counterproductive features in the way you reason and the invention of alternative action strategies is not enough to enable participants to produce more effective action. Our frame for the solution to the problem of increasing teaching effectiveness needs to be expanded. It should include the identification (and change) of the underlying values of the theory-in-use that informs these counterproductive strategies and holds them in place.

This revised frame would lead us to make additional interventions the next time we run such a workshop for faculty. These interventions would be designed to go beyond identifying how the undesired consequences were the result of the strategies used. We would connect the strategies the participants were using to the underlying values these were designed to satisfy. The following two samples illustrate the type of interventions we are suggesting.

\section{Sample Intervention 1}

I: $K$, when you say that the student will not admit he was scowling or frowning by saying "I just dropped my pencil" or "That's how I look when I'm concentrating," are you saying he is more interested in protecting his version of the facts and that he will not own up to the truth? 


\section{Assume K says yes.}

I: I see you using the fact that he will deny what you say he did as a reason for not testing the validity of your interpretation. If that is true, then you are protecting your version of the truth. You are behaving in the same way that you criticize the student for behaving. Does this make sense to you?

\section{Sample Intervention 2}

$\mathrm{I}$ : $\mathrm{K}$, in your case write up you criticize the student for expressing his negative emotions and judgments and for trying to influence or control you and the situation. Would you agree?

Assume K says yes.

I: I infer that you are also trying to control the situation. You do this at first by withholding your negative judgments and emotions. Eventually you try to control the situation by expressing your negative judgements emotionally. You are behaving in the same way that you criticize the student for behaving. Do you agree with this analysis?

Assume $\mathrm{K}$ agrees.

I: The alternative that we are proposing is that you share the control by striving to produce the valid information necessary for free and informed choices by both you and the student. Inquiry and problem solving are at the core of this approach. It requires both of you to illustrate and test the validity of your attributions and evaluations.

We will be able to assess the adequacy of this revised frame and the new interventions by examining how faculty members react in future workshops.

In this paper we have proposed that increasing teaching effectiveness requires that faculty members reflect on their own practice as teachers. Faculty developers also need to reflect on their practice of trying to help faculty. The theory-of-action perspective directs reflection on practice to the identification of the counterproductive features in how professionals reason in order to act as they do. Thus, in our analysis we focused on how faculty members were reflecting in the difficult situations in their teaching practice. This paper illustrates how the theory-of-action perspective influenced our reflection-in-action in our working with faculty, how we were reasoning in order to act as we did.

Cross (1987) has called for faculty to take more responsibility for improving teaching by becoming "classroom researchers," that is, by assessing the effectiveness of their actions in producing student learning in their own classrooms. Reflection on practice as we have described it is a form of classroom research. In this paper we have identified some of the fea- 
tures this reflection must have in order for it to improve teaching practice.

\section{Notes}

1. The research reported in this paper was made possible by a grant from the Professional and Organizational Development Network in Higher Education. A version of this paper was presented at the American Educational Research Association Meetings in New Orleans, 1988.

2. Conducting the workshop and writing this paper were done collaboratively and the order of authors on the paper does not signify any priority.

\section{Bibliography}

Argyris, C. (1982). Reasoning, Leaming and Action. San Francisco: Jossey Bass.

Argyris, C., Schon, D. (1974). Theory in Practice: Increasing Professional Effectiveness. San Francisco: Jossey Bass.

Argyris, C., Putnam, R., Smith, D. (1985). Action Science. San Francisco: Jossey-Bass.

Cross, K. P. (1987). The need for classroom research. In J. Kurfiss, L. Hilsen, L. Mortensen, \& R. Wadsworth. (Eds.) To Improve the Academy, Vol. 6 (pp. 3-17). The Professional and Organizational Development Network in Higher Education.

Schon, D. (1983). The Reflective Practitioner: How Professionals Think in Action. New York: Basic Books.

Schon, D. (1987). Educating The Reflective Practitioner. San Francisco: Jossey-Bass.

Smith, R. A. (1983). A Throey of Action Perspective on Faculty Development. In M. Davis, M. Fisher, S. Inglis, \& S. Scholl (Eds.), To Improve the Academy, Vol. 2 (pp. 47-58). The Professional and Organizational Development Network in Higher Education.

Smith, R. A., Schwartz, F. (1986). A Theory of Effectiveness: Faculty Development Case Studies. Joumal of Staff, Program \& Organizational Development, 4(1), 3-8. 